\title{
Advancing U.S.-México Science through the Education Network Effect
}

\author{
Enrique R. Vivoni \\ Arizona State University \\ Tempe, Arizona, USA 85287
}

Considering the current relations between the U.S. and México, one might question if vigorous scientific interactions are occurring in the areas of interest to Atmósfera. With the political rhetoric exhibiting a trend towards protectionism, how could binational efforts possibly flourish? Even prior to the current environment, annual trends of student exchanges between the two countries show a stagnation in activity over the last decade (IIE, 2018). Specifically, there have been about 15,000 Mexican students at higher education institutions in the U.S. and about 5,000 U.S. citizens studying abroad in México each year. These rates of student exchange are extremely low given the overall populations in higher education $(19,000,000$ in U.S. and 4,000,000 in México, UIS, 2019). With this limited student mobility, a fair question is whether this affects the production and dissemination of scientific knowledge as related to Atmósfera.

The annual trends cited above include both undergraduate and graduate students, as well as short-term exchanges not leading to a degree. The situation is more concerning when we focus on graduate degrees, which are of higher value for the production of scientific knowledge. Indeed, IIE (2018) indicate that about 4,000 Mexican students per year are in graduate programs in the U.S. during 2016-2018. While it is difficult to know the number of graduate students in the areas of Atmósfera, we can ascertain that these numbers are small. First, the physical and earth sciences represented only $6 \%$ of graduate enrollment from international students in the U.S. (CGS, 2018). Second, the number of applications of Mexican students to graduate programs in the U.S. has been falling (CGS, 2018). Third, México is below average in terms of the percent of doctoral recipients in the natural sciences at only $10 \%$ as compared to $23 \%$ in other countries (OECD, 2019). This 
evidence points to a dire situation in graduate education with respect to mobility between the U.S. and México. While there are other options, including higher education in each country or in other regions of the world, bilateral U.S. and México exchanges promote the study of shared challenges.

Graduate education is the most potent pathway for transforming society. The academic, research and practitioner communities all require students traversing this educational pipeline. Such is the case for Atmósfera given that advanced training is a prerequisite for professions in meteorology, hydrology and oceanography. For instance, the challenges faced in managing concepts and tools to provide solutions under growing demands and climate change. Along the U.S.-México border, graduate education in hydrology must also expose students to the realities imposed by differences in sociopolitical context, while also providing a solid foundation in water resources topics. Specifically, the U.S.-México border is undergoing radical transformations in land and water use (Bohn et al., 2018; Vivoni and Bohn, 2018) that require assessments to understand its broad impacts, including upon regional climate.

Binational, interdisciplinary and societally relevant challenges of the type exemplified above cannot be addressed in isolation. There must be a convergence of interests in both the United States and México, as well as an alignment of investments of time, effort and financial resources. It is important to note that there have been several successful examples of binational collaboration within the topic areas of Atmósfera. Figure 1 shows an analysis of three field projects that involved scientists from the U.S. and México: (1) the México City Metropolitan Area Field Campaigns (2003-2006), (2) the North American Monsoon Experiment (2000-2008), and (3) the Colorado River Delta Pulse Flow (2012-2017). For each project, the number of institutions from both countries exceeded nearly a dozen. In each case, a Web of Science analysis was conducted using the project names as keywords. By these scientific metrics, each project has yielded an impressive engagement in peer- 
reviewed publications whose impact in the form of citations continues well after the initial investments. Furthermore, the projects engaged a large number of undergraduate and graduate students from each country. This training yielded a generation of professionals in the U.S. and México capable of conducting binational, interdisciplinary efforts for the benefit of society in each country.

How can the scientific communities represented in Atmósfera capitalize on the success of these binational projects? For instance, an important lesson of the North American Monsoon Experiment was how to use the shared monsoon system as a tool for communicating to a broad set of stakeholders. In addition, these binational topics motivated students to participate and continue engaging in these scientific disciplines. Indeed, the project catalyzed activities spanning nearly two decades due to the student pipeline established in the field project. Thus, lessons from prior efforts can serve as a model for future initiatives that aim to achieve a sustained and self-reinforcing impact to society. The first lesson is that a focus needs to be placed on shared problems that clearly transcend disciplinary and geographic boundaries as these allow for an equitable adoption of common objectives. Second, it is critical to design a student engagement pipeline such that short-term exchanges and mobility across institutions in each country are promoted. Clearly, graduate education is central to both of these pursuits in that research relies heavily on the efforts of graduate students and in that sustaining a scientific pursuit over several decades requires entraining new generations into the endeavor.

Several issues need to be addressed when designing a binational effort that can impact society through knowledge dissemination. As a first example, research projects are typically limited in duration, in particular when centered on a field experiment. As the field activities end, the period of intense, binational collaboration is replaced with the work of smaller groups in individual institutions. Secondly, the coordination of activities in a binational network are often reliant on the efforts of individual institutions without the proper use of a central hub. This leads to missed 
opportunities for exchanges, information losses among partners, repetitive efforts, and often the disengagement of participants and students. Finally, the full spectrum of initiatives from universities, research centers and partnering organizations are not typically activated due to the focus on research activities. If the participating institutions were able to include other aspects of higher education, such as degree programs, community engagement, or fundraising, additional opportunities would be available to sustain the activities.

How can we design a long-lasting binational initiative in the subject areas of interest to Atmósfera? Along the U.S.-México border, a compelling design focuses on shared processes and phenomena that have implications on binational relations, socioeconomic development, and human well-being. There a number of possible broad areas that could be explored, including earth system hazards, climate change impacts, natural resources management, or energy production, among others. From a pragmatic perspective, it will be necessary to select an area of interest in order to build the collaborator network necessary to operationalize the effort. However, the design should be flexible enough to be applied across different subject areas by different sets of collaborators. Figure 2 illustrates this design using the water resources of the U.S.-México border as an example. The design consists of a number of elements. First, the binational network is formed by a set of interacting institutions of different types and of varying sizes and specializations. A network model is setup with a centralized hub in each country serving as an integrator and liaison in each socioeconomic and political context. A strong collaboration is required between the two central hubs such that cross-border coordination is facilitated. Other institutional participants might have more limited connections in the network and their interactions might change over time. Second, the linkages in the network are expected to be multidimensional in that institutional partners would seek to have activities in the academic, research, fundraising, and knowledge dissemination realms. Note that not all types of activities would be required for participation. Instead, the binational network would promote interactions that expand research 
efforts into degree granting programs, for instance, that would lead to student mobility. Establishing collaborative degrees by more than one institution would advance a scientific field, train future generations of students, and provide a mechanism for sustaining efforts beyond the lifetime of individual research projects.

Capitalizing on prior efforts, a group of collaborating institutions along the U.S.-México border is developing the Border Institute for the Nexus of Climate, Land and Water, or Border Nexus Institute, as an example of a binational network. The Border Nexus Institute has an interdisciplinary focus that brings together expertise from atmospheric science, hydrology and land use science, among others, to address regional challenges of a scale not possible by any single institution. This effort is a response to the call to action by Vivoni and Bohn (2018) who show the need for studies of the consequences of binational trade on land and water resources along the U.S.-México border. More specifically, rapid land cover alterations in both countries, including agricultural extensification in México and urbanization in the U.S., have the potential to impact regional climate and water supplies in unintended ways. While there has not been a formal launch of the institute, institutional partners, research groups and regional projects are being identified through a grassroots approach. The Border Nexus Institute follows the schematic in Figure 2, with a focus on providing participation in different modes, through academic, research and knowledge dissemination pathways, as well as the flexible and coordinated structure offered by a binational network. In addition, the design is sufficiently broad to allow for other topics, including transboundary water resources, extreme climatic events, and the link between terrestrial conditions and warm season precipitation.

While rooted in the scientific topics of interest to Atmósfera, the Border Nexus Institute aims to provide societal benefits through the application of observations, models and analysis tools. In that respect, this binational effort is open to those institutions in the private, non-profit, philanthropic and government sectors 
with an interest in advancing science as well as in translating research into practitioner use. This can be achieved both through research activities for the public benefit of the region, as well as through the advanced training of a future workforce exposed to multiple career pathways. Indeed, as a network built upon the infrastructure of higher education, an important outcome will be the establishment of new models for graduate and postdoctoral studies which provide opportunities for student mobility, collaborative degrees and joint research. This "education network effect" promises to advance U.S.-México science in the areas of interest to Atmósfera. In this way, the binational network will also serve as an inflection point on the currently stagnant educational exchange between the U.S. and México, perhaps serving as a model for other disciplines to emulate. 


\section{ATMÓSFERA

\section{References}

Bohn, T.J., Vivoni, E.R., Mascaro, G., and White, D.D. (2018). Land and water use changes in the US-Mexico border region, 1992-2011. Environmental Research Letters, 13(11): 114005. https://doi.org/10.1088/1748-9326/aae53e

Council of Graduate Schools (2019). International Graduate Applications and Enrollment: Fall 2018. Okahana, H. and Zhou, E., Washington, D.C., Available at: http://www.cgsnet.org//ckfinder/userfiles/files/Intl Survey Report Fall2018.pdf.

Institute of International Education (2018). Open Doors Report on International Educational Exchange. Available at: https://www.iie.org/en/Research-andInsights/Open-Doors/Fact-Sheets-and-Infographics/Leading-Places-of-Origin-FactSheets.

Organisation for Economic Cooperation and Development (2019). Mexico: Education at a Glance, OECD Indicators. Available at:

https://www.oecd.org/education/education-at-a-glance/EAG2019 CN_MEX.pdf.

UNESCO Institute for Statistics (2019). UIS Education Data Release, September 2019. Information Paper 59. Available at: http://data.uis.unesco.org.

Vivoni, E.R., and Bohn, T.J. (2018). ¿Ha impactado el TLCAN los recursos de agua y uso del suelo en la frontera de México y EE.UU.? GEOS, 38(2): 1-3. 


\section{Figures}
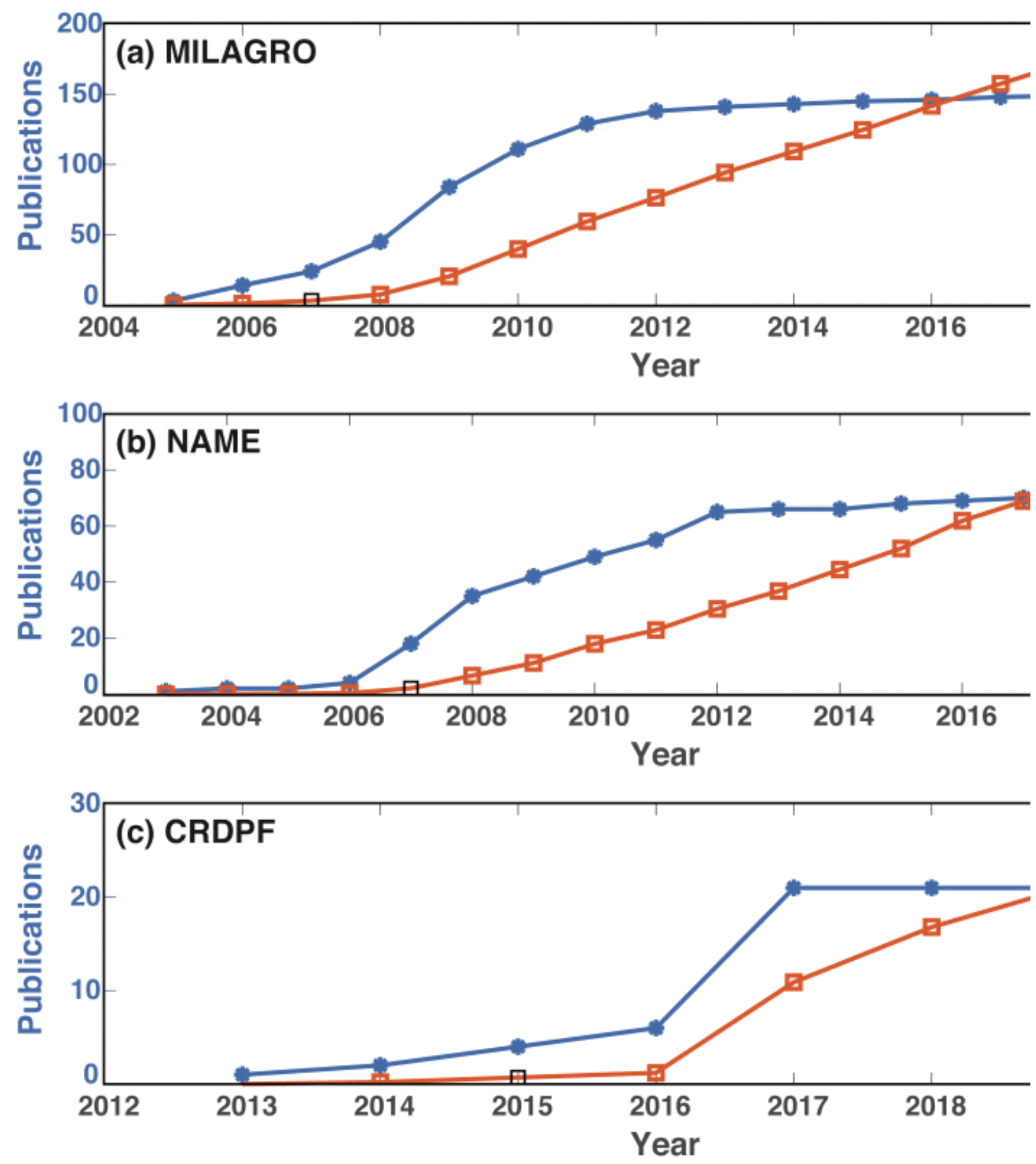

Figure 1. Citation metrics of collaborative U.S.-México field projects obtained from a Web of Science analysis on November 25, 2019 for: (a) México City Metropolitan Area Field Campaigns, (b) North American Monsoon Experiment, and (c) Colorado River Delta Pulse Flow. 


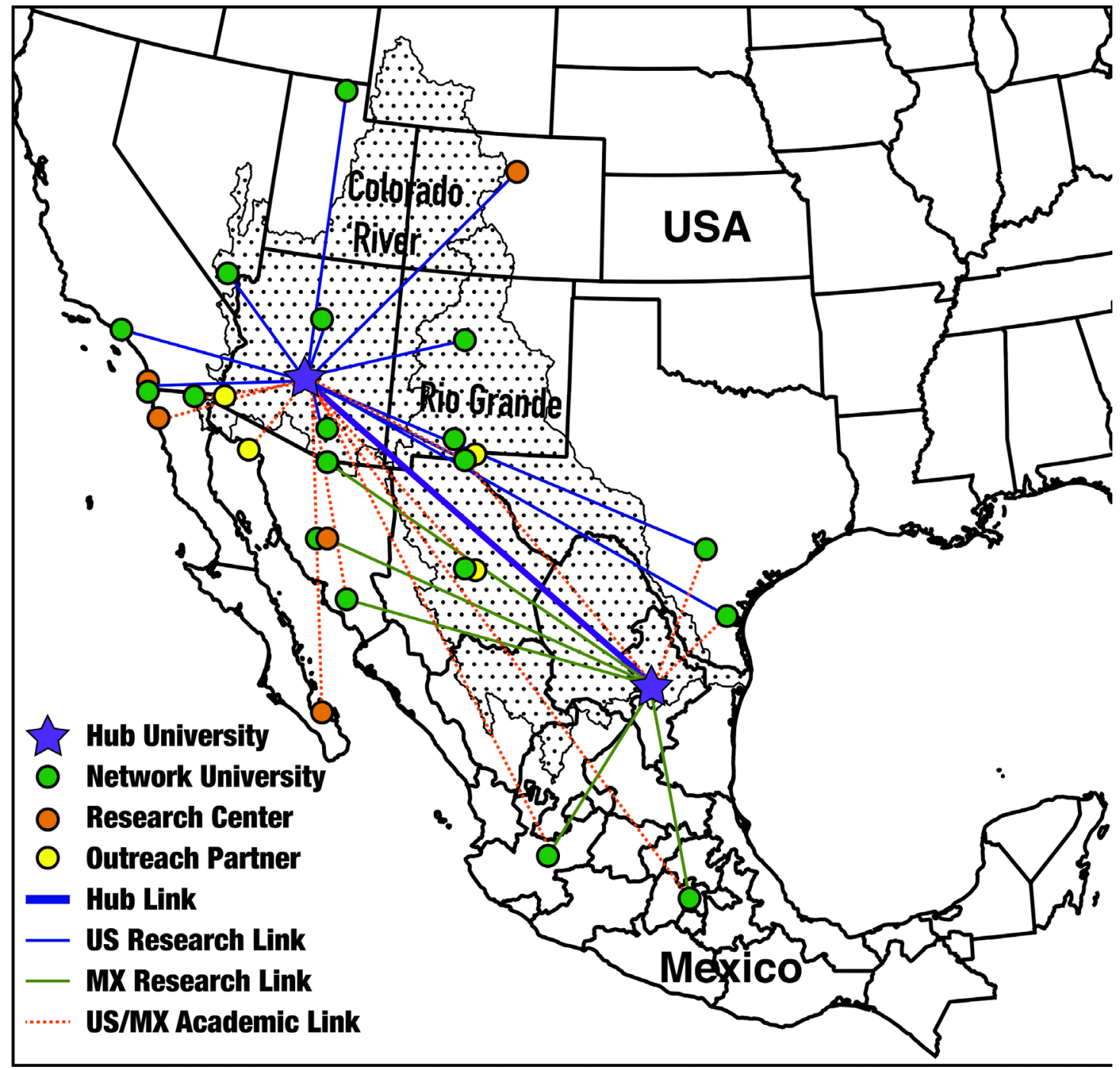

Figure 2. Schematic map for the Border Institute for the Nexus of Climate, Land and Water illustrating a design consisting of: (1) university hubs in the U.S. and México, (2) network universities and research centers, and (3) outreach partners from the practitioner community. 